\title{
Bicuspid aortic valve: what should I know? Updated review of its clinical and pathophysiological aspects
}

\author{
Válvula aórtica bicúspide: ¿qué debo conocer? Revisión actualizada de sus aspectos \\ clínicos y fisiopatológicos
}

\author{
Alejandro Junco-Vicente ${ }^{1 *}$, Isabel Rodríguez ${ }^{2,3}$, Guillermo Solache-Berroca²,3, Helena Cigarrán ${ }^{4}$, and \\ María Martín ${ }^{1,2}$
}

${ }^{1}$ Department of Cardiology, Hospital Universitario Central de Asturias, Oviedo; ${ }^{2}$ Cardiac Pathology Research Group, Instituto de Investigación Sanitaria del Principado de Asturias, Oviedo; ${ }^{3}$ Red Temática de Investigación Cooperativa en Salud (REDinREN), Instituto de Salud Carlos III, Madrid; ${ }^{4}$ Department of Radio-diagnosis, Hospital Universitario Central de Asturias, Oviedo. Spain

\begin{abstract}
The most common congenital heart disease in the general population is the bicuspid aortic valve. Far from being just a harmless valve malformation, it is a complex and heterogeneous disease. It is often identified as an incidental finding in healthy people. However, in a high percentage of patients, it leads throughout their life toward valvular (stenosis, insufficien$c y$, and endocarditis) or aortic (dilatation or dissection) complications. Frequently, manifestations occur at an early age, being responsible for high morbidity and mortality. Even though in recent years intense research has been carried out in this field, the pathophysiogenesis of the disease is not fully known and many questions remain open. In this article, we review the most innovative and relevant clinical and pathophysiological aspects of this congenital heart disease.
\end{abstract}

Key words: Bicuspid aortic valve. Bicuspid aortopathy. Congenital heart disease.

\section{Resumen}

La válvula aórtica bicúspide es la cardiopatía congénita más frecuente en la población general. Lejos de ser solo una mal formación valvular inocua, supone una enfermedad compleja y heterogénea. A menudo es identificada como un hallazgo incidental en personas sanas, cursando de manera asintomática. Sin embargo, en un alto porcentaje de pacientes conduce a lo largo de su vida a complicaciones valvulares (estenosis, insuficiencia, endocarditis) o aórticas (dilatación o disección). Con frecuencia estas manifestaciones suceden a una edad temprana y causan una elevada morbimortalidad. A pesar de que en los últimos años se ha producido una intensa investigación en este campo, la fisiopatoge nia de la enfermedad no es del todo conocida y muchas preguntas siguen abiertas. En este artículo se revisan de forma actualizada los aspectos clínicos y fisiopatológicos más novedosos y relevantes sobre esta cardiopatía congénita.

Palabras clave: Válvula aórtica bicúspide. Aortopatía bicúspide. Cardiopatía congénita.

\section{Correspondence:}

${ }^{\star}$ Alejandro Junco-Vicente

E-mail: ajuncovicente@gmail.com
Available online: 02-03-2021

Arch Cardiol Mex (Eng). 2020;90(4):482-490

www.archivoscardiologia.com
Date of acceptance: 02-06-2020

DOI: 10.24875/ACME.M20000158 license (http://creativecommons.org/licenses/by-nc-nd/4.0/). 


\section{Introduction}

Bicuspid aortic valve (BAV) is the most common congenital heart disease in the general population. Far from being just a harmless valve malformation, it entails a complex and heterogeneous disease ${ }^{1}$. Its spectrum can consist, at its most benign extreme, of an incidental finding, remaining as a subclinical anomaly throughout life, or, at a more serious extreme, become the origin of a valve dysfunction that may be decisive for patient short-term prognosis'. Within this inter-individual clinical dispersion, complications in middle adulthood are known to be common, conferring a much heavier burden of morbidity than any other congenital heart disease $^{2}$. In consequence, there has been progressive scientific interest on BAV in recent years, with important advances in the field of embryology and genetics that seek to explain the etiology of this malformation. Light has been shed on its pathogenesis and on its high association with aortic dilatation, with which sometimes it is currently comprised within the same syndrome. As a result of this growing knowledge, the reason for this article arises, whereby we expect to review the most relevant aspects of this congenital heart disease.

\section{Anatomy and morphological subtypes}

The first anatomical descriptions of this valve anomaly are classically attributed to Leonardo da Vinci, in the $15^{\text {th }}$ century. Today, BAV is defined as the existence of two valve leaflets, although there is great individual variability with regard to the valve detailed characteristics: symmetry, presence of raphe, nature of the commissures, etc. ${ }^{1-3}$. One of the leaflets is mainly generated by the fusion or lack of separation of two of the primitive leaflets during valve development. Thus, the two leaflets are usually uneven in size, with the fused one having a larger surface. On the other hand, in most bicuspid valves, there is a raphe, that is, a fibrous ridge directed from the free border of the valve to the arterial wall, which represents the "junction zone" of the larger leaflet components. The shape of the valve opening and the raphe position (when present) will define the different BAV subtypes. There are several classifications described by different authors ${ }^{4-6}$, but one of the most widely used is that of Sievers and Schmidtke ${ }^{4}$. These authors differentiate three subtypes according to the absence of raphe or presence of one or two raphes (types 0,1 , and 2 , respectively), and then they make a subdivision according to the raphe and leaflets spatial position. Thus, in type 0 , in which there is no raphe ("pure" BAV), there are two subcategories: (1) lateral position, with the leaflets being right and left, and (2) leaflets anteroposterior position. In type 1, there are three anatomical leaflets, but two functional leaflets due to the presence of the raphe; it is the most common type. The raphe can be located between the left and right leaflets $(L-R)$, which is the most common subtype; between the right and non-coronary leaflets (R-N); or, finally, between the non-coronary and left leaflet (N-L), which is the least common subtype of all three. Finally, and infrequently, type 2 has two raphes, present in practically all cases between the left and right leaflets $(L-R)$ and between the right and non-coronary leaflets (R-N) (Fig. 1).

\section{Epidemiology}

BAV estimated prevalence in the literature ranges from $0.5 \%$ to $2 \%$ of the population ${ }^{1,2,7}$, although the real prevalence is not entirely known because no extensive population screening exists and because, on many occasions, it has an asymptomatic evolution. Most of the classic studies were carried out in cohorts of Caucasian patients, but studies in other populations already exist in the literature, with geographic variations being observed in terms of prevalence. Thus, a similar prevalence has been described in the Asian population ${ }^{8}$. In the population native to sub-Saharan Africa, there is disagreement regarding prevalence, but it appears to be lower ${ }^{9}$. In a Central American study with 2750 unselected patients who attended to have an echocardiogram practiced, BAV was observed in $4.9 \%$ of them ${ }^{10}$. A low prevalence has been described among the Afro-American and Caribbean population, which ranges from $0.11 \%$ to $0.28 \%{ }^{11}$. It predominates in the male gender (around 3:1) ${ }^{3}$. An interesting screening study carried out by Tutar et al. ${ }^{12}$ in newborns describes a higher prevalence in boys (7.1/1000 boys) than in girls (1.9/1000 girls). These gender differences suggest that the $\mathrm{X}$ chromosome may play an important role in its origin, also supported by the high incidence of BAV in Turner syndrome ${ }^{13}$.

\section{Diagnosis}

Diagnosis is usually established after auscultation of an aortic stenosis or aortic regurgitation murmur, after the appearance of symptoms or incidentally during an echocardiographic study. Diagnosis is based on two-dimensional transthoracic echocardiography imaging, and thus is it referred in current clinical practice guidelines: "transthoracic echocardiography is the recommended imaging modality for the initial assessment of 


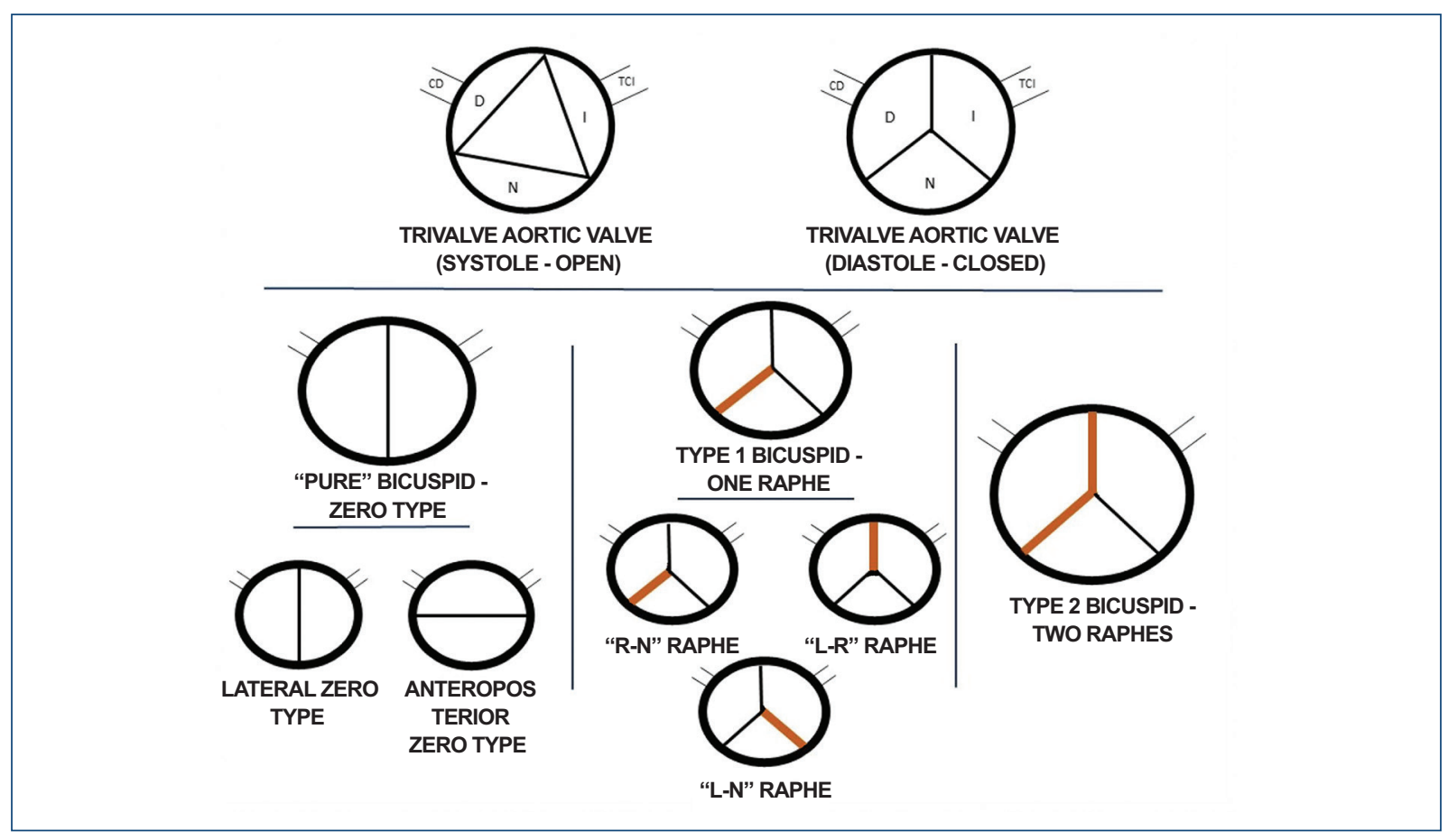

Figure 1. Diagram of bicuspid valve types classification according to Sievers and Schmidtke ${ }^{4}$. CD: right coronary artery; D: right coronary sinus; I: left coronary sinus; L: left; N: non-coronary sinus; R: right; TCl: left coronary trunk.

the aortic valve and thoracic aorta, including the assessment of hemodynamic aortic valve function;" with class I scientific evidence ${ }^{14}$. This type of non-invasive diagnosis, applicable to large population groups, has enabled the performance of larger studies on BAV. For diagnosis to be established, the valve must be visualized in systole (open valve) in a parasternal view over the short axis. It should not be performed in diastole (closed valve), since the raphe can make the valve appear as a TriValve, generating confusion ${ }^{3,14,15}$. When the valve is highly calcified, as it occurs in advanced stenosis, differentiating the valve cusps is more difficult and diagnosis is less accurate. Transesophageal ultrasound offers a more detailed and better-quality view, and it can therefore be used when there are doubts. Sometimes, other diagnostic imaging tests, such as cardiac magnetic resonance imaging (MRI) or computed tomography (CT), help to confirm the diagnosis of congenital malformation, although these techniques are usually more often used to study the aorta $3,15,16$.

\section{Etiopathogenic aspects}

At present, bicuspid valve abnormal development is integrated in the so-called left ventricular outflow tract anomalies, included in this spectrum together with coarctation of the aorta, hypoplastic left heart syndrome, etc. For example, approximately $50 \%$ of patients with coarctation have associated $\mathrm{BAV}^{3,13,15}$ (Fig. 2). In addition, a marked genetic heterogeneity underlying BAV is observed, thus appearing linked to different chromosomal abnormalities and genetic diseases $^{13}$. A higher prevalence of BAV has been described in Down syndrome (trisomy 21) or in DiGeorge syndrome (monosomy 22q11), as well as in Turner syndrome, with a prevalence of $15-30 \%$ in patients with this condition; also in Marfan syndrome, Loeys-Dietz syndrome, and William-Beuren syndrome ${ }^{13}$. Although over the past few decades there has been great interest for discovering the mechanisms that lead to the formation of bicuspid valve disease, the genes and the interrelationships of the molecules involved in left ventricular outflow tract normal development are not yet adequately understood. Several signaling pathways that are key to normal morphological development of the heart have been associated with BAV: tumor growth factor beta (TGF- $\beta$ ) superfamily, GATA family, Tbx20, nitric oxide synthase 3 (eNOS3), NOTCH1, or Wnt/ $\beta$-catenin, among others ${ }^{1,15,17,18}$. BAV development is known not to be due to a single gene 


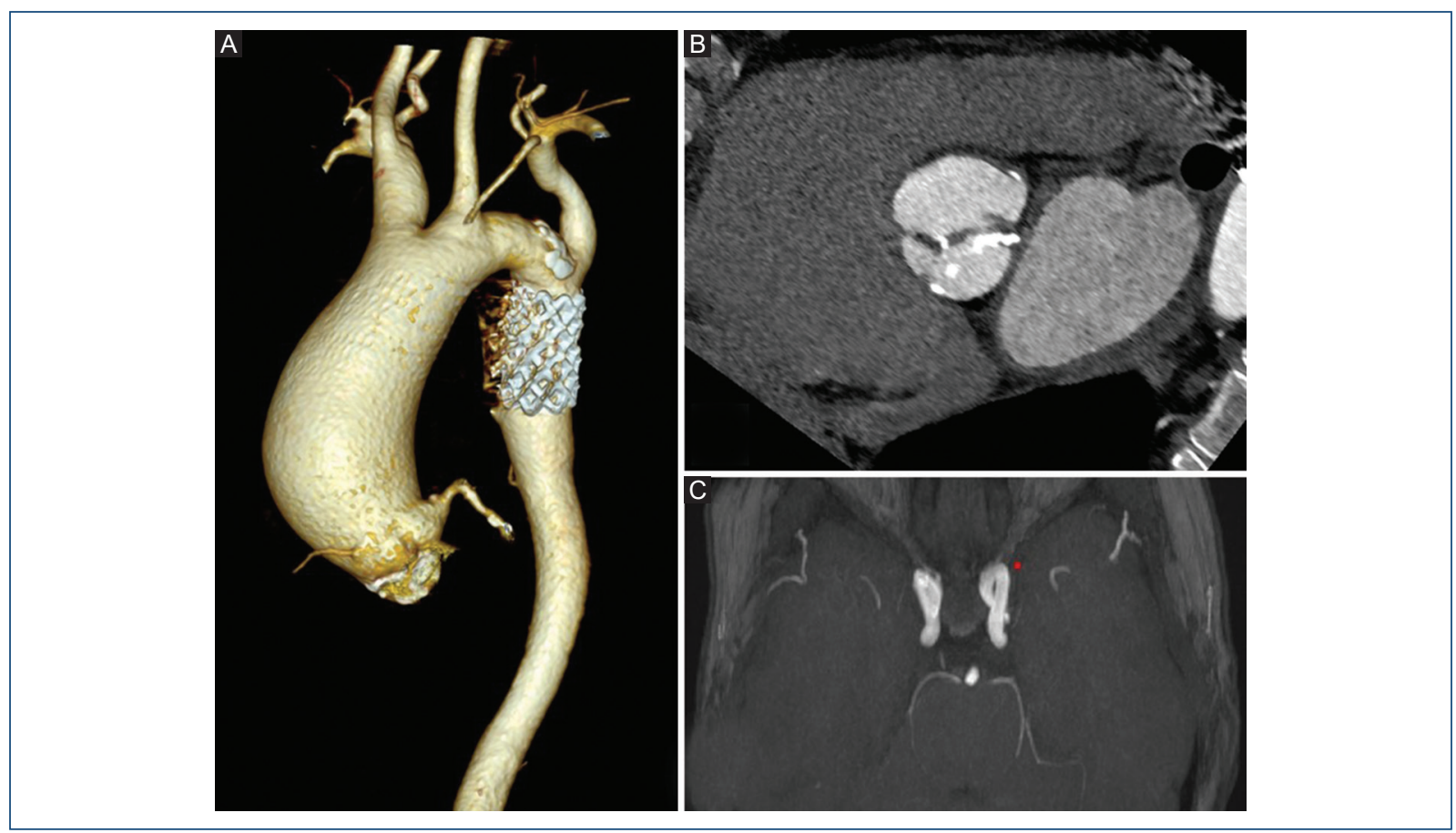

Figure 2. Patient with bicuspid aortopathy and coarctation of the aorta operated on in adulthood by stent implantation. A: Three-dimensional computed tomography (CT) reconstruction showing an aneurysm of the ascending aorta and the stent in the coarctation area. B: CT showing the bicuspid aortic valve with calcification areas on its leaflets. C: patients with coarctation of the aorta may exhibit Willis polygon aneurysms, and their screening is therefore recommended.

and, currently, for a better classification of related mutations, two groups are distinguished. On one hand, there are genetic alterations described in patients with BAV that is related to clinical syndromes, such as mutations in FBN1 (Marfan syndrome) or TGFBR1/2 (Loeys-Dietz syndrome) ${ }^{18}$. On the other hand, there are non-syndromic alterations, for example, mutations in GATA5, PITX2, or CLIP21,18. Among the sporadic or non-syndromic forms, mutations in the NOTCH1 gene are the most widely studied. Families with mutations in this gene that behaves with a dominant autosomal inheritance pattern have been described. NOTCH1 signaling pathways are highly preserved between species, since they have a key role in cell differentiation, cell development, and intercellular communication processes and play a crucial function in embryonic organogenesis and particularly in cardiovascular system development ${ }^{18}$. In addition, NOTCH1 inhibition leads, in turn, to defective signaling in the TGF- $\beta$ pathway, with a relationship existing between both these pathways, which affects the correct remodeling of the vascular matrix and aortic valve correct development. The GATA family of transcription factors has been involved in cell differentiation processes ${ }^{18}$. Several genes, GATA4, GATA5, and, more recently, GATA6, have been associated with the development of BAV ${ }^{18-20}$. NOS protein has also been related to valve morphogenesis. Specifically, NOS-3, which is constitutive of vascular tissue, exhibits mutations related to the development of $B A V^{18}$. Not only genetic but also epigenetic studies (gene expression heritable changes with no changes in DNA sequence) are strongly emerging in the field of BAV. Mechanisms related to DNA methylation, histone modifications, etc., have been studied. One study demonstrated hypermethylation of the region corresponding to GATA4 and hypomethylation in ACTA2 in individuals with $B A V$, in comparison with control subjects ${ }^{21}$. BAV-related microRNA and IncRNA (long non-coding RNA) have also been studied. In a large study with microarrays, Yanagawa et al. ${ }^{22}$ demonstrated differential expression of 34 microRNAs when comparing patients with BAV and tricuspid aortic valve (TAV) and identified miR-141 as a regulator of accelerated valve calcification. Despite the great efforts in recent years, with a multitude of investigations in this field of scientific knowledge, the ontogenetic basis of the development of BAV remains unknown. 


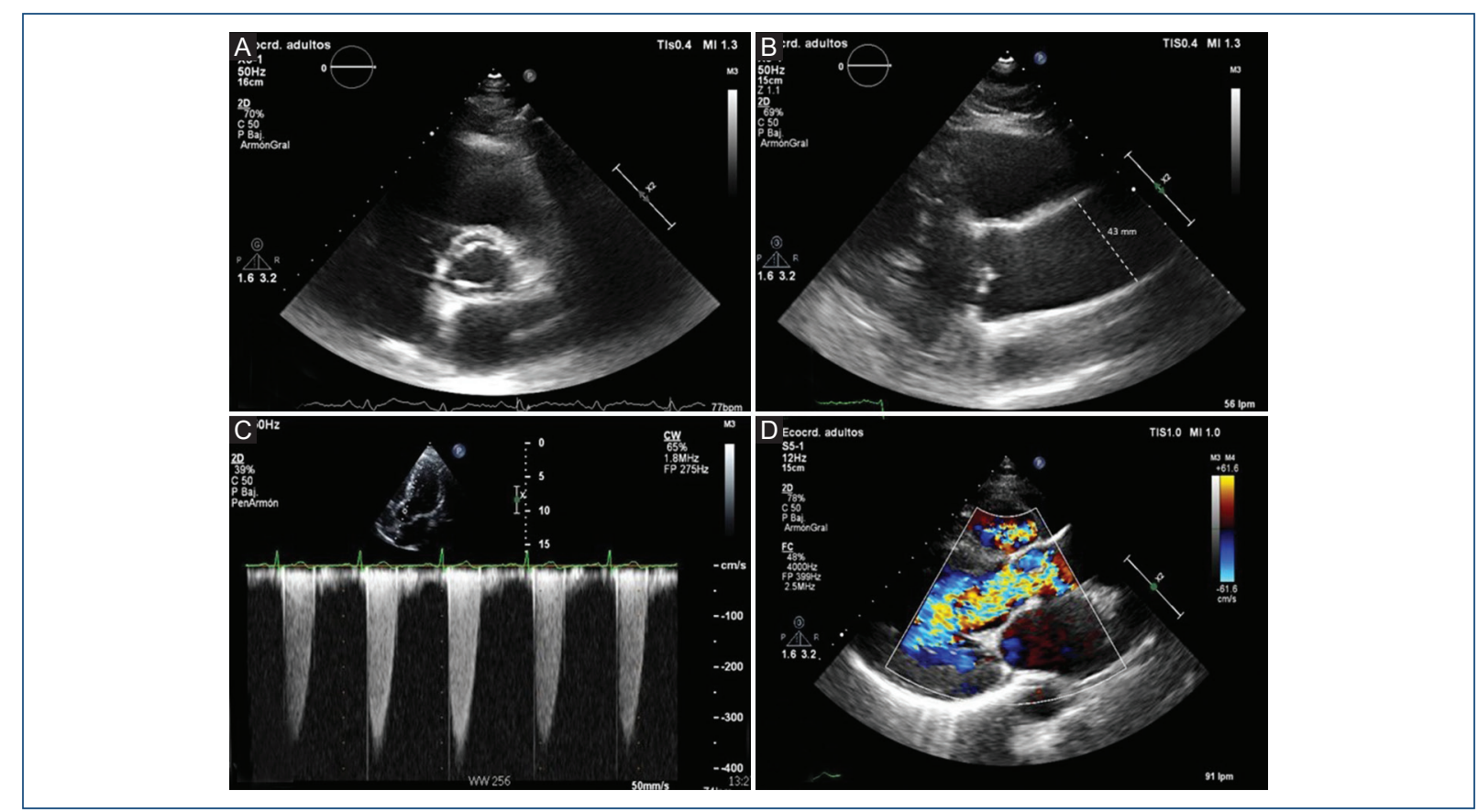

Figure 3. Transthoracic echocardiogram images. A: parasternal view at the short axis showing a type 1 bicuspid aortic valve (fusion of the right and left coronary leaflets) open in systole. B: plane at the level of the aortic root and ascending aorta showing significant aortic dilatation $(43 \mathrm{~mm})$. C: aortic transvalvular gradient by continuous Doppler showing elevated velocities and gradients typical of significant aortic stenosis. D: Color Doppler showing a diastolic regurgitation jet that occupies the entire left ventricular outflow tract, typical of severe aortic regurgitation, in a patient with bicuspid valve disease.

\section{Family screening, is it necessary?}

Genetic and epigenetic determinants, as we have seen, are complex, and BAV is therefore associated with different patterns of inheritance. In many cases, an autosomal dominant family inheritance with low penetrance and variable expressiveness is described ${ }^{17}$. Screening studies in first-grade relatives of patients with BAV show variable prevalence within a range of between $4 \%$ and $22 \%$, although a prevalence of around $10 \%$ has traditionally been established in first-degree relatives ${ }^{17,21}$. There is also evidence of a higher prevalence of BAV among first-degree relatives of patients with some congenital heart diseases, such as coarctation of the aorta, septal defects, and aortic dilatation. Based on these data, clinical practice guidelines recommend the screening of first-degree relatives of patients with BAV with transthoracic echocardiography ${ }^{14,17}$.

\section{Clinical course and complications}

Given that only symptomatic patients, with or without valve disease, seek medical attention, there is a gap in the knowledge about the real consequences of having BAV. Thus, it is possible that current knowledge on the disease does not to adjust to reality, given that only those individuals with complications are observed in medical practice. Different prospective studies have attempted to evaluate the natural course of congenital heart disease, with a wide variability of presentations and behaviors being demonstrated, ranging from the development of a severe stenosis in childhood to having an asymptomatic course practically during the entire adult life $e^{1,3,15,23}$

The most common complication in patients with BAV is valve dysfunction due to stenosis or regurgitation ${ }^{1,3}$ (Fig. 3). In childhood, the typical course is asymptomatic. In youth and early adulthood, most medical consultations and surgical interventions are for severe aortic regurgitation ${ }^{23,24}$. The etiological mechanism can be functional, due to dilatation of the aortic root, or primary valvular due to prolapse, myxomatous degeneration, or endocarditis. Subsequently, individuals tend to develop aortic stenosis due to an accelerated valve calcification process, requiring intervention at an age 20-30 years younger than patients with stenotic TAV ${ }^{23-26}$. From a 


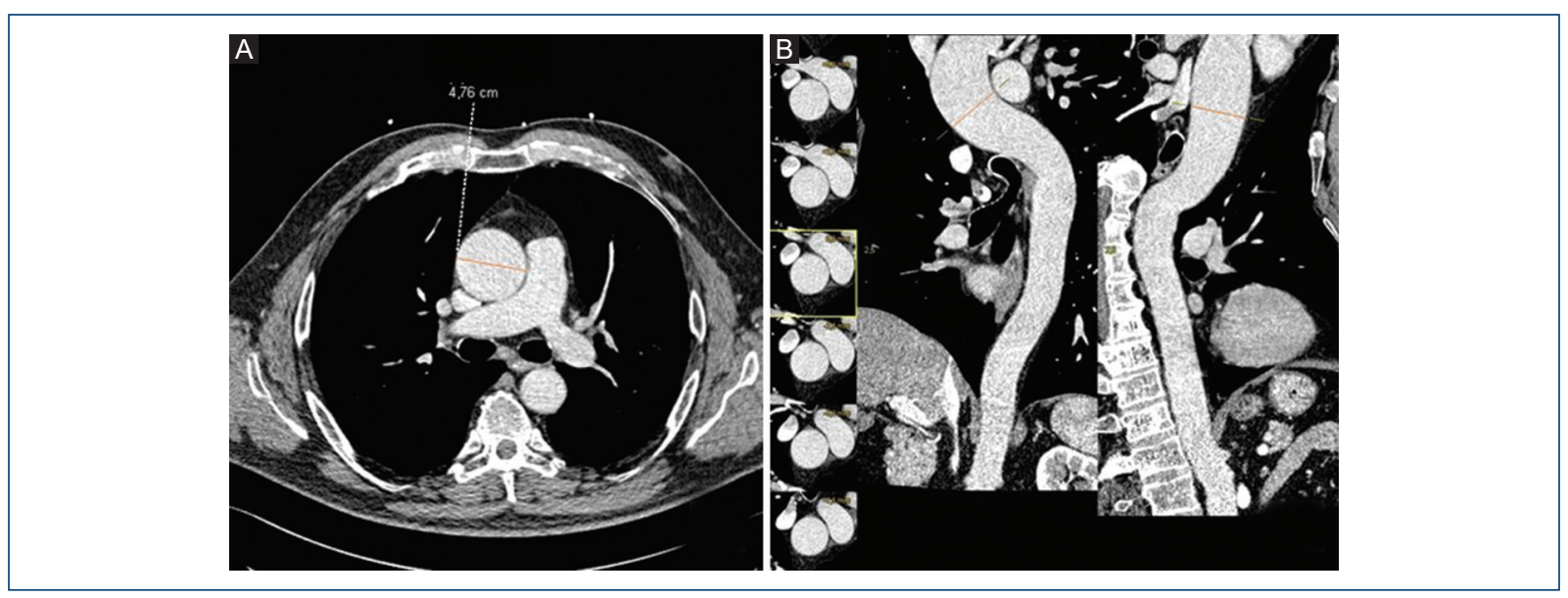

Figure 4. Computed tomography of the aorta. A: axial plane at the level of the great vessels showing significant dilatation of the ascending thoracic aorta $(4.76 \mathrm{~mm})$. B: Oblique reconstructions of the aorta where dilatation of the ascending aorta is observed.

morphological point of view, calcification appears to occur in a similar way as in TAV. Current research attempts to elucidate if the variability in the age of calcification presentation in BAV versus TAV is predominantly due to mechanical or genetic factors ${ }^{1,15}$. The management of aortic stenosis and aortic regurgitation should be the same in patients with BAV than in those with TAV, following current clinical practice guidelines ${ }^{14,27,28}$.

The most common association is with thoracic aortic dilation and aneurysms, which is why some current publications encompass them within the same syndrome (Fig. 4). Patients with BAV, in comparison with those with TAV, have been shown to be at higher risk of developing ascending aorta dilatation and aortic dissection ${ }^{5,15}$. However, data on the prevalence of the association are variable (33-80\% of BAV cases), perhaps due, apart from the heterogeneity inherent to the disease, to a lack of consensus in the studies on the measurements to define dilatation, the imaging techniques that are used, the region of the aorta that is considered, etc. There is disagreement about whether or not the different bicuspid valve morphotypes are predictors of higher risk of aortic dilatation ${ }^{23,29}$. The etiology and pathogenesis of aortic dilatation in patients with BAV is so far uncertain, but two theories are proposed. There are authors who advocate for the hemodynamic-mechanical hypothesis. Mechanical stress on the aortic wall has been studied by means of four-dimensional MRI flow analysis. Due to BAV anomalous opening, an eccentric flow directed against the aortic wall is formed, and it would be this constant tangential force that ultimately generates the dilatation ${ }^{29,30}$. Other authors support the genetic hypothesis, which postulates that there are genetic alterations that are common to the risk of aortic aneurysm development and BAV onset. The fact that aortopathy has been shown to be more frequent in first-degree relatives of individuals with BAV supports this theory ${ }^{21}$. The close relationship in embryonic development between semilunar valves and the remodeling of the aortic root and ascending aorta is also known; and, in turn, the participation of neural crest cells both in valve and aortic wall development has been demonstrated ${ }^{31}$. As a result, alterations in intracellular and intercellular signaling might justify the coexistence of both pathologies.

A non-valvular but highly feared complication is aortic dissection. Patients with BAV have a higher prevalence of aortic dilatation and, therefore, higher risk in these cases of aortic dissection, an acute pathology that is associated with high rate mortality when it occurs. It usually takes place in the ascending aorta ${ }^{23}$. Although the described incidence is variable, in large population-based follow-up series, it is low $(<0.5 \%)^{23-25}$. In childhood, aortic dissections are extremely rare. However, in cases of Marfan syndrome with aortic wall dilatation, there is higher risk of aortic dissection in childhood or adolescence, a fact that is associated with high morbidity and mortality in these patients ${ }^{32}$.

Another non-valvular complication that has been classically associated with BAV is infectious endocarditis. The risk of endocarditis described in the early series was very high (10-30\%), ${ }^{2}$ and thus clinical practice guidelines recommended antibiotic prophylaxis for all patients with BAV. However, more recent and larger 
series estimate that the incidence of endocarditis in this population subgroup is much lower, of $0.3-2 \%^{23,24}$. For this reason, current European and American clinical practice guidelines do not recommend antibiotic prophylaxis in these patients, except in those with a history of endocarditis ${ }^{33}$.

Despite all these possible complications, the cohort follow-up series confirm an important fact: in current era, individuals with BAV do not have a shorter life expectancy than the rest of the population. In asymptomatic adults with BAV and different degrees of valve dysfunction, 10-year survival was $96 \pm 1 \%^{24}$, and in asymptomatic adults with BAV without significant valve dysfunction, 20-year survival was $90 \pm 3 \%^{23}$.

As for patient follow-up, it will depend on the symptoms and on the appearance of complications. Periodic transthoracic echocardiograms are usually performed during the follow-up of an asymptomatic patient to rule out the appearance of silent complications, such as valve dysfunction or aortic dilatation. When there is valve dysfunction, clinical practice guidelines recommendations for valvular heart disease $e^{14,27,28}$ are followed: in case of mild-moderate insufficiency, an echocardiogram will be performed every 2 years, and if severe, at 1 year; in case of stenosis, if calcification is significant within the mild-moderate range, an echocardiogram will be performed every year, and if it is severe, every 6 months. If there is dilatation of the ascending aorta or aortic root, carrying out a control using an imaging technique once a year is recommended. While it is true that, if there is an adequate acoustic window, transthoracic echocardiography is useful for aortic measurements to be carried out in patient follow-up, this window often is not optimal and can generate measurement errors. MRI and CT use a "double oblique" measurement technique that provides a more accurate measurement of the aortic segment ${ }^{15}$. In case of any increase in aortic diameter, it is recommended to confirm it with CT or MRI. Based on this, there are authors who advocate for the follow-up of the patient with aortic dilatation to be carried out with these imaging tests.

\section{Surgical treatment, when is it indicated?}

The indications for acting on valve dysfunction in patients with BAV are the same as in those with TAV. According to the guidelines, symptomatic patients with severe valve dysfunction, both regurgitation and stenosis, should be offered valve intervention ${ }^{14,27,28}$. In addition, it should also be recommended to patients who are asymptomatic, but with severe failure with left ventricular ejection fraction $<50 \%$, left ventricular end-diastolic diameter $>70 \mathrm{~mm}$, or left ventricular end-systolic diameter $>50 \mathrm{~mm}^{27,28}$. In asymptomatic patients who are to undergo other cardiac surgery, acting on the aortic valve should be considered in case of severe valve dysfunction ${ }^{28}$. Valve replacement with a mechanical or biological prosthesis is the treatment of choice, with a 15-year survival rate of around $80 \%{ }^{15}$. One-year complication rate is $3-5 \%{ }^{34}$. It should be borne in mind that, in the case of BAV, since patients are younger and have a longer life expectancy, they are more susceptible to complications associated with prosthetic replacement, either secondary to the need for anticoagulation, risk of thrombosis or thromboembolism in mechanical prostheses, or prosthetic degeneration in biological prostheses, or endocarditis development in both ${ }^{34}$. Although valve replacement is the standard procedure, aortic valve repair should be considered in centers with high experience, since its long-term durability and lower complication rate versus valve replacement have been demonstrated. In patients with comorbidity, not susceptible to heart surgery, consideration should be given to percutaneous valve replacement ${ }^{34,35}$. The performance of transcatheter aortic valve implantation in patients with BAV shows a higher degree of complexity and requires a detailed study of the aortic annulus and individual selection of the most appropriate prosthesis; and it continues to have poorer results than in patients with $\mathrm{TAV}^{35}$. Although a meta-analysis describes similar mortality, need for pacemaker implantation, and stroke rate in comparison with tricuspid aortic stenosis, subjects with BAV continue to be shown to have a significantly lower success rate with the implant, higher peri-procedural complications, more moderate/severe residual para-prosthetic insufficiency, and a higher rate of surgical reconversion ${ }^{35}$.

\section{Other aspects}

\section{Medical treatment}

Optimal control of blood pressure figures is recommended in these patients ${ }^{14}$. In addition, with a low level of evidence and extrapolated from studies carried out in populations with connective tissue diseases, mainly Marfan syndrome, the use of beta-blockers and renin-angiotensin system blockers is recommended as preferred drugs ${ }^{14}$. 


\section{Pregnancy}

Pregnancy will not entail a problem for a woman without significant valve dysfunction and with no aortic root dilation ${ }^{1,15}$. Aortic valve regurgitation is generally well tolerated by healthy women during pregnancy. This does not occur with moderate or severe aortic stenosis, which generates greater cardiovascular health problems with frequent decompensation and need for hospitalization due to heart failure ${ }^{36,37}$. Therefore, avoiding pregnancy if there is known significant stenosis is recommended. In case this is unknown, it is possible to perform a rescue aortic valvuloplasty if it becomes necessary. Pregnancy with aortic dilatation is usually safe, with dissections being an infrequent event ${ }^{37}$. In clinical practice guidelines, pregnancy is not recommended in patients with severe aortic dilatation (inherited diseases of the thoracic aorta, such as Marfan syndrome $>45 \mathrm{~mm}, \mathrm{BAV}>50 \mathrm{~mm}$, and aortic dimension $>27 \mathrm{~mm} / \mathrm{m}^{2}$ of body surface), although there is insufficient scientific evidence behind this expert recommendation ${ }^{37}$. Performing serial ultrasounds during pregnancy if there is a diagnosis of aortic dilatation is recommended ${ }^{38}$.

\section{Physical exercise}

Given that BAV affects young patients, recommendations regarding physical exercise are important. However, there is little scientific data on the subject. Considering that physical exercise benefits on health have been demonstrated, every physician should make recommendations about it to his/her patients with $\mathrm{BAV}^{7}$. For symptomatic patients, avoiding exercise is recommended; for asymptomatic patients with severe insufficiency associated with left ventricle dilatation or severe stenosis, not participating in sports competitions and not overexerting themselves is recommend$\mathrm{ed}^{14,39}$. In those with or without significant valve dysfunction who have aortic root dilatation (>40 mm), only moderate exercise and not to participate in high-intensity sports competitions, or performing isometric exercises is recommended ${ }^{39}$. There are many asymptomatic patients with BAV and mild-to-moderate valve dysfunction who wish to practice physical exercise for pleasure or for its benefits for health; although there is no scientific evidence in this regard, the recommendation is that they can practice moderate physical exercise. They should be advised that in the event of any symptoms such as angina, palpitations, or dyspnea, they should stop exercising. Finally, it is important bearing in mind that patients with BAV without valve dysfunction or aortic root dilatation $(<40 \mathrm{~mm})$ should not be recommended restrictions regarding physical exercise $^{7,39}$.

\section{Funding}

The authors declare that there are no conflicts of interest or funding.

\section{Conflicts of interest}

The authors declare that there are no conflicts of interest.

\section{Ethical disclosures}

Protection of human and animal subjects. The authors declare that no experiments were performed on humans or animals for this research.

Confidentiality of data. The authors declare that no patient data appear in this article.

Right to privacy and informed consent. The authors declare that no patient data appear in this article.

\section{References}

1. Pedersen MW, Groth KA, Mortensen KH, Brodersen J, Gravholt $\mathrm{CH}$, Andersen $\mathrm{NH}$. Clinical and pathophysiological aspects of bicuspid aortic valve disease. Cardiol Young. 2019;29:1-10.

2. Ward C. Clinical significance of the bicuspid aortic valve. Heart. 2000;83:81-5.

3. Siu SC, Silversides CK. Bicuspid aortic valve disease. J Am Coll Cardiol. 2010;55:2789-90.

4. Sievers HH, Schmidtke C. A classification system for the bicuspid aortic valve from 304 surgical specimens. J Thorac Cardiovasc Surg. 2007;133:1226-33.

5. Russo CF, Cannata A, Lanfranconi M, Vitali E, Garatti A, Bonacina E. Is aortic wall degeneration related to bicuspid aortic valve anatomy in pa-tients with valvular disease? J Thorac Cardiovasc Surg. 2008;136:937-42.

6. Schaefer BM, Lewin MB, Stout KK, Gill E, Prueitt A, Byers PH, et al. The bicuspid aortic valve: an integrated phenotypic classification of leaflet morphology and aortic root shape. Heart. 2008;94:1634-8.

7. Stout KK, Daniels CJ, Aboulhosn JA, Bozkurt B, Broberg CS, Colamn JM, et al. 2018 AHA/ACC Guideline for the management of adults with con-genital heart disease: a report of the American College of Cardiology/American Heart Association Task Force on Clinical Practice Guidelines. Circulation. 2019;139:e698-800.

8. Li Y, Wei X, Zhao Z, Liao Y, He J, Xiong T, et al. Prevalence and com-plications of bicuspid aortic valve in Chinese according to echocardiogra-phic database. Am J Cardiol. 2017;120:287-91.

9. Mucumbitsi J, Bulwer B, Mutesa L, Ndahindwa V, Rusingiza E, Puneeta A, et al. Prevalence of rheumatic valvular heart disease in Rwandan school children: echocardiographic evaluation using the World Heart Federation criteria. Cardiovasc J Afr. 2017;28:1-8.

10. Domínguez-Díaz AE, Cerrud-Sánchez CE, Alva-Espinosa C, David-Gómez F, Yáñez-Gutiérrez L, López-Gallegos D. Aorta bivalva: frecuencia y lesiones asociadas. Estudio prospectivo en 2,750 ecocardiogramas consecutivos. Rev Mex Cardiol. 2013;24:184-8.

11. Khan W, Milsevic M, Salciccioli L, Lazar J. Low prevalence of bicuspid aortic valve in African Americans. Am Heart J. 2008;156:e25.

12. Tutar E, Ekici $F$, Atalay S, Nacar N. The prevalence of bicuspid aortic valve in newborns by echocardiographic screening. Am Heart $\mathrm{J}$. 2005;150:513-5. 
13. Niaz T, Poterucha JT, Olson TM, Johnson JN, Craviari C, Nienaber T, et al. Characteristic morphologies of the bicuspid aortic valve in patients with genetic syndromes. J Am Soc Echocardiogr. 2018;31:194-200.

14. Borger MA, Fedak PWM, Stephens EH, Gleason TG, Girdauskas E, Ikonomidis JS, et al. The American Association for Thoracic Surgery consensus guidelines on bicuspid aortic valve-related aortopathy: exe-cutive summary. J Thorac Cardiovasc Surg. 2018;156: 473-80.

15. Martín M, Lorca R, Rozado J, Álvarez-Cabo R, Calvo J, Pascual I, et al Bicuspid aortic valve syndrome: a multidisciplinary approach for a complex entity. J Thorac Dis. 2017:9:454-64.

16. Tanaka R, Yoshioka K, Niinuma H, Ohsawa S, Okabayashi H, Ehara S. Diagnostic value of cardiac CT in the evaluation of bicuspid aortic ste-nosis: comparison with echocardiography and operative findings. AJR Am J Roentgenol. 2010;195:895-9.

17. Freeze SL, Landis BJ, Ware SM, Helm BM. Bicuspid aortic valve: a review with recommendations for genetic counseling. J Genet Couns. 2016;25:1171-8

18. Balistreri CR, Forte M, Greco E, Paneni F, Cavarretta E, Frati G, et al. An overview of the molecular mechanisms underlying development and progression of bicuspid aortic valve disease. J Mol Cell Cardiol. 2019;132:146-53.

19. Alonso-Montes C, Martín M, Martínez-Arias L, Coto E, Naves-Díaz M Morís C, et al. Variants in cardiac GATA genes associated with bicuspid aortic valve. Eur J Clin Invest. 2018:48:e13027.

20. Gharibeh L, Komati H, Bossé Y, Boodhwani M, Heydarpour M, Fortier M et al. GATA6 regulates aortic valve remodeling and its haploinsufficiency leads to right-left type bicuspid aortic valve. Circulation. 2018;138: 1025-38.

21. Hales AR, Mahle WT. Echocardiography screening of siblings of children with bicuspid aortic valve. Pediatrics. 2014;133:e1212-7.

22. Yanagawa B, Lovren F, Pan Y, Garg V, Quan A, Tang G, et al. miR NA-141 is a novel regulator of BMP-2-mediated calcification in aortic stenosis. J Thorac Cardiovasc Surg. 2012;144:256-62.

23. Michelena HI, Desjardins VA, Avierinos JF, Russo A, Nkomo VT, Sundt TM, et al. Natural history of asymptomatic patients with normally functioning or minimally dysfunctional bicuspid aortic valve in the com-munity. Circulation. 2008;117:2776-84.

24. Tzemos N, Therrien J, Thanassoulis G, Tremblay S, Jamorski MT, Webb GD, et al. Outcomes in adults with bicuspid aortic valves. JAMA 2008;300:1317-25.

25. Rodrigues I, Agapito AF, de Sousa L, Oliveira JA, Branco LM, Galrinho A et al. Bicuspid aortic valve outcomes. Cardiol Young. 2017;27:518-29.

26. Roberts WC, Ko JM. Frequency by decades of unicuspid, bicuspid, and tricuspid aortic valves in adults having isolated aortic valve replacement for aortic stenosis, with or without associated aortic regurgitation. Circu-lation. 2005;111:920-5.
27. Nishimura RA, Otto CM, Bonow RO, Carabello BA, Erwinlll JP, Fleisher LA, et al. 2017 AHA/ACC focused update of the 2014 AHA/ACC guideline for the management of patients with valvular heart disease: a report of the American College of Cardiology/American Heart Associa-tion Task Force on Clinical Practice Guidelines. Circulation. 2017;135:e1159-95.

28. Baumgartner H, Falk V, Bax JJ, De Bonis M, Hamm C, Holm PJ, et al. 2017 ESC/EACTS guidelines for the management of valvular heart di-sease. Eur Heart J. 2017;38:2739-91.

29. Mahadevia R, Barker AJ, Schnell S, Entezari P, Kansal P, Fedak PW, et al. Bicuspid aortic cusp fusion morphology alters aortic three-dimen-sional outflow patterns, wall shear stress, and expression of aortopathy. Circulation. 2014;129:673-82

30. Rodríguez-Palomares JF, Dux-Santoy L, Guala A, Kale R, Maldonado G, Teixidó-Turà $G$, et al. Aortic flow patterns and wall shear stress maps by 4D-flow cardiovascular magnetic resonance in the assessment of aortic dila-tation in bicuspid aortic valve disease. J Cardiovasc Magn Reson. 2018;20:28.

31. Phillips HM, Mahendran P, Singh E, Anderson RH, Chaudhry B, Hender-son DJ. Neural crest cells are required for correct positioning of the developing outflow cushions and pattern the arterial valve leaflets. Car-diovasc Res. 2013;99:452-60.

32. Groth KA, Stochholm K, Hove H, Kyhl K, Gregersen PA, Vejlstrup N et al. Aortic events in a nationwide Marfan syndrome cohort. Clin Res Cardiol. 2017;106:105-12.

33. Habib G, Lancellotti P, Antunes MJ, Bongiorni MG, Casalta JP, Del Zotti F, et al. 2015 ESC guidelines for the management of infective endocarditis: The Task Force for the Management of Infective Endocar-ditis of the European Society of Cardiology (ESC). Eur Heart J. 2015; 36:3075-123.

34. Aicher D, Fries R, Rodionycheva S, Schmidt K, Langer F, Schäfers HJ. Aortic valve repair leads to a low incidence of valve-related complications. Eur J Cardiothorac Surg. 2010;37:127-32.

35. Ueshima D, Fovino LN, Brener SJ, Fabris T, Scotti A, Barioli A, et al. Transcatheter aortic valve replacement for bicuspid aortic valve stenosis with first and new generation bioprostheses: a systematic review and meta-analysis. Int J Cardiol. 2020;298:76-82.

36. Orwat S, Diller G-P, van Hagen IM, Schmidt R, Tobler D, Greutmann M, et al. Risk of pregnancy in moderate and severe aortic stenosis: from the multinational ROPAC registry. J Am Coll Cardiol. 2016;68:1727-37.

37. Regitz-Zagrosek V, Roos-Hesselink JW, Bauersachs J, Blomström-Lundqvist C, Cífková R, De Bonis M, et al. ESC 2018 guidelines for the ma-nagement of cardiovascular diseases during pregnancy. Eur Heart $\mathrm{J}$. 2018;39:3165-241.

38. McKellar SH, MacDonald RJ, Michelena HI, Connolly HM, Sundt TM 3rd. Frequency of cardiovascular events in women with a congenitally bicus-pid aortic valve in a single community and effect of pregnancy on events. Am J Cardiol. 2011;107:96-9.

39. Gati S, Malhotra A, Sharma S. Exercise recommendations in patients with valvular heart disease. Heart. 2019;105:106-10. 